The Effect of Narcissistic Admiration and Rivalry on Speaking Performance

Manley, Harry; Paisarnsrisomsuk, Nuttha; Roberts, Ross

\title{
Personality and Individual Differences
}

DOI:

10.1016/j.paid.2019.109624

Published: 01/02/2020

Peer reviewed version

Cyswllt i'r cyhoeddiad / Link to publication

Dyfyniad o'r fersiwn a gyhoeddwyd / Citation for published version (APA):

Manley, H., Paisarnsrisomsuk, N., \& Roberts, R. (2020). The Effect of Narcissistic Admiration and Rivalry on Speaking Performance. Personality and Individual Differences, 154, [109624]. https://doi.org/10.1016/j.paid.2019.109624

\footnotetext{
Hawliau Cyffredinol / General rights

Copyright and moral rights for the publications made accessible in the public portal are retained by the authors and/or other copyright owners and it is a condition of accessing publications that users recognise and abide by the legal requirements associated with these rights.

- Users may download and print one copy of any publication from the public portal for the purpose of private study or research.

- You may not further distribute the material or use it for any profit-making activity or commercial gain

- You may freely distribute the URL identifying the publication in the public portal?
}

Take down policy

If you believe that this document breaches copyright please contact us providing details, and we will remove access to the work immediately and investigate your claim. 
The Effect of Narcissistic Admiration and Rivalry on Speaking Performance

\author{
${ }^{1}$ Harry Manley*, ${ }^{1}$ Nuttha Paisarnsrisomsuk, ${ }^{2}$ Ross Roberts \\ ${ }^{1}$ Faculty of Psychology, Chulalongkorn University, Bangkok, Thailand \\ ${ }^{2}$ Institute for the Psychology of Elite Performance, Bangor University, UK
}

Correspondence to. Harry Manley, Faculty of Psychology, Chulalongkorn University, Bangkok, Thailand. e-mail: harrisonmanley@gmail.com, twitter: @ harrisonmanley

Declaration of Interest. None

Supplementary. https://osf.io/2hyuf/

This paper is in press, cite as.

Manley, H., Paisarnsrisomsuk, N., \& Roberts, R. (In press). The Effect of Narcissistic

Admiration and Rivalry on Speaking Performance. Personality and Individual Differences 


\begin{abstract}
Objective. A narcissistic individual can seek to maintain his/her grandiose self-view through different processes associated with assertive self-enhancement (narcissistic admiration) or antagonistic self-protection (narcissistic rivalry). Here, we examine how admiration and rivalry affect anxiety and performance in a speaking task. Because the behaviours associated with narcissistic rivalry are motivated by ego threat, we further examined the moderating effect of self-affirmation, a process designed to reduce ego threat, on performance.

Method. We assigned 90 Thai students to a self-affirmation or control group and asked them to deliver a short speech. We assessed speech performance through self-report and observer ratings, and state anxiety using self-report.

Results. Narcissistic admiration was adaptive for speech performance and predicted higher self and observer-rated speech performance and lower anxiety. In contrast, narcissistic rivalry was associated with greater anxiety but was unrelated to speech performance. Self-affirmation moderated the effect of narcissistic rivalry on self-rated speech performance but in an unexpected direction such that rivalry was negatively related to speech performance following self-affirmation.
\end{abstract}

Conclusion. These results add to the developing literature on the behavioural correlates of narcissistic admiration and rivalry, with admiration reflecting the more socially adaptive component of grandiose narcissism. 


\section{The Effect of Narcissistic Admiration and Rivalry on Speaking Performance}

\section{Introduction}

Do narcissistic individuals make effective public speakers? Delivering a speech that will be evaluated by others can be a highly stressful and threatening task (Kirschbaum, Pirke, \& Hellhammer, 1993), yet it is also an opportunity for garnering the attention and admiration of others. These are salient factors for narcissistic individuals seeking to maintain or enhance their grandiose self-image. Across a wide range of performance domains, narcissistic grandiosity is consistently associated with good performance when the task affords an opportunity for personal glory (for a review see: Roberts, Woodman, \& Sedikides, 2018). Specifically, when narcissistic individuals are presented with such opportunities (e.g., through the presence of a crowd), they raise their performance level relative to when admiration is less readily available (Wallace \& Baumeister, 2002). Although the effect of narcissism has been well-studied in various cognitive and motor tasks, a notable omission is the absence of any understanding of the effects of narcissism on public speaking performance. This is perhaps surprising given that public speaking is an interpersonal domain with wide relevance. Only a limited few have their careers defined by the execution of a motor skill under pressure, whereas the ability to speak in public (e.g., a business pitch, job interview, etc.) is an important domain for an individual's personal and professional success. In the present study we consider how dimensions of grandiose narcissism are associated with public speaking performance.

\subsection{Narcissistic Admiration and Rivalry}

Grandiose narcissism has often been conceptualised as a unidimensional construct associated with a range of paradoxical behaviours. For example, narcissistic individuals can be charming and self-assured in one moment and defensive and hostile in the next (Bushman \& 
Baumeister, 1998; Twenge \& Campbell, 2003). In light of these contradictory behaviours, it is increasingly well recognised that narcissism is better viewed as a heterogenous trait comprising different factors associated with divergent outcomes (Crowe, Lynam, Campbell, \& Miller, 2019; Krizan \& Herlache, 2018; Miller, Lynam, Hyatt, \& Campbell, 2017). One model of narcissism with promise for resolving these paradoxes argues that the motivations and behaviours of narcissistic individuals can be better understood by considering narcissism through two related dimensions of narcissistic admiration and narcissistic rivalry (Back et al., 2013).

The narcissistic admiration and rivalry concept (NARC; Back et al., 2013) proposes that a fundamental goal of the narcissistic individual is to maintain a grandiose self-view. However, this goal can be achieved through two pathways associated with narcissistic admiration and rivalry. Admiration is aligned with the motivation to satisfy the grandiose self through assertive self-enhancement. Individuals are motivated to strive for uniqueness and approach this through self-assured, dominant, and expressive behavioural responses that result in positive social outcomes such as praise, social status or acceptance as a leader. In contrast, rivalry is associated with the motivation to protect against threats to the grandiose self-image. This defensive approach to avoid social failure is associated with overt displays of aggressive and antagonistic behaviours (Leckelt, Küfner, Nestler, \& Back, 2015). Importantly, the NARC proposes that individuals differ not only in the degree to which they possess a grandiose self-image but also in the degree to which they activate assertive self-promotion (i.e., admiration) and antagonistic selfdefence (i.e., rivalry) as a means to maintain their self-image.

Back et al. (2013; Study 7) examined the effect of admiration and rivalry on behaviour during a brief speaking task and, in support of the assertive processes associated with narcissistic admiration, found that admiration predicted greater use of agentic behaviours such as expressive 
gestures and overall self-assuredness. In contrast, and in support of the antagonistic processes associated with narcissistic rivalry, rivalry was associated with the use of fewer communal behaviours, such as smiling and displaying warmth. This evidence suggests that admiration and rivalry affect the behavioural characteristics of speech in different ways and these may in turn influence perceptions of speech quality. Narcissistic admiration is also positively associated with the tendency to self-select for public self-enhancement opportunities (i.e., training to be an actor), whereas rivalry repels individuals from the limelight (Dufner et al., 2015). More generally, admiration correlates with low anxiety, low rumination and high well-being whereas rivalry correlates with insecure striving styles and greater negative affect (Grove, Smith, Girard, \& Wright., 2019). Further, there is evidence that admiration and rivalry have positive and negative effects, respectively, on individual's (athlete's) ability to cope with stressful situations (Manley, Jarukasemthawee, \& Pisitsungkagarn, 2019). Thus, there are contrasting correlates and motivational dynamics of admiration and rivalry that appear highly relevant for determining how each dimension of narcissism is associated with speech performance.

\subsection{The Present Study}

Despite the accumulating evidence of how narcissistic admiration and rivalry might influence performance in evaluative domains, it is unknown exactly how admiration and rivalry relate to speech performance. In the present study, we examined the effect of narcissistic admiration and rivalry on participants performance delivering an improvised speech in a studio setting where we measured state anxiety, and self and observer ratings of speech performance. Based on the contrasting dynamics of admiration and rivalry, we had two main hypotheses regarding the effects of admiration and rivalry on speaking performance. Hypothesis 1 stated that narcissistic admiration would facilitate speech performance, increasing the quality of speech and 
reducing anxiety. Specifically, we predicted that admiration would be positively related to both self and observer-rated speech performance and negatively related to state anxiety. In contrast, hypothesis 2 stated that rivalry would be associated with increased anxiety and decreased speech performance. Specifically, we predicted that rivalry would be negatively related to self and observer-rated speech performance and positively related to state anxiety ${ }^{1}$.

In recognition that ego threat is proposed to be an important dynamic for rivalry, but not admiration, a secondary focus of the present research was to consider whether a self-affirmation intervention to reduce ego threat would moderate the rivalry - speech performance relationship. Self-affirmation is a process whereby individuals affirm positive aspects of their self, directing attention to general concepts of their self-integrity rather than specific threats (Steele, 1988). Self-affirmation interventions typically involve asking participants to focus on an important personal value, such as their belonging to a social group, and this has consistently been shown to buttress self-esteem, reducing anxiety and vulnerability to ego threats (Creswell et al., 2005). Self-affirmations interventions have also been demonstrated to be effective in reducing aggression displayed by narcissistic children when their egos are threatened (Thomaes et al., 2016). Consequently, self-affirmations may be an effective strategy to attenuate any negative behavioural responses associated with rivalry. To examine the effect of self-affirmation we assigned participants to either a control or self-affirmation group, prior to the speech task. Hypothesis 3 stated that the self-affirmation intervention would attenuate any negative effect of rivalry on performance. Compared to the control condition, rivalry would lead to less anxiety and better speech performance following the use of self-affirmation.

\footnotetext{
${ }^{1}$ We report here the main hypotheses defined at the outset of the preregistration. We note that in the preregistration there are inconsistencies in how we specified the hypotheses for the effect of rivalry on anxiety and self-rated performance.
} 


\section{Method}

All data and analysis scripts are available on the Open Science Framework (https://osf.io/qyxz9/?view_only=29149afbb452405085f74bc0c397efe0). Preregistration of the main hypotheses is available online (https://osf.io/j9k7s?view_only=54791f987fbd403a89fd11dbbb5d67ae). We completed preregistration after data from 82 of the 90 participants had been collected but before the data were inspected or analysed.

\subsection{Participants}

We recruited 90 Thai undergraduate students ( 68 females, $M$ age $=19.50, S D=1.22)$ to participate in this study in exchange for course credit. Power analysis (G*Power; Faul, Erdfelder, Lang, \& Buchner, 2007) indicated that 77 participants were required to have .80 power to detect a small-tomedium size main effect (i.e., a partial $r^{2}$ of 0.15 ) of narcissistic admiration and rivalry on outcome variables. Although the study was powered to detect these main effects, it was not sufficiently powered to detect the potentially smaller moderating effect of self-affirmations. We used a stratified random sampling method (controlling for sex) to assign participants into either a self-affirmation $(n=44)$ or control $(n=46)$ group. All participants provided written consent and the study was approved by the local institute research ethics committee.

\subsection{Measures $^{2}$}

\footnotetext{
${ }^{2}$ In addition to the procedures described, we also recorded participants skin conductance and cardiovascular activity. The physiological measures were designed to provide objective measures of anxiety during the speech. However, due to technical issues, reliable and complete physiological data were only available for a limited subset of participants and are not reported here. We also assessed participants dispositional public speaking anxiety and observers provided ratings for additional items (agentic and communal) speech behaviours; see supplementary.
} 
Participants completed measures assessing narcissism, state anxiety, self-esteem and selfratings of speech performance. We translated all measures from English to Thai according to procedures outlined by Brislin (1970). Means, standard deviations and reliability for each scale in the present sample are displayed in Table 1.

2.2.1 Narcissism. We assessed narcissistic admiration and rivalry using the 18 -item Narcissistic Admiration and Rivalry Questionnaire (NARQ; Back, Küfner, Dufner, Gerlach, \& Rauthmann, 2013) Nine items measured narcissistic admiration (e.g., "Being a very special person gives me a lot of strength"); nine items measured narcissistic rivalry (e.g., "I secretly take pleasure in the failure of my rivals"). Responses were measured on a six-point Likert scale from 1 (strongly disagree) to 6 (strongly agree).

2.2.2 Self-integrity. We used the eight-item self-integrity scale (Sherman et al., 2009) to determine the efficacy of the self-affirmation manipulation. The self-integrity scale includes statements assessing general moral and adaptive adequacy, e.g., "On the whole, I am a capable person". Responses were measured on a seven-point Likert scale from 1 (strongly disagree) to 7 (strongly agree).

2.2.3 Self-esteem. We assessed self-esteem using the ten-item Rosenberg Self-Esteem Scale (Rosenberg, 1979). Responses were measured on a five-point Likert scale from 1 (strongly disagree) to 5 (strongly agree). An item example is "I feel that I have a number of good qualities". Higher scores indicate higher self-esteem.

2.2.4 State anxiety. We measured state anxiety at baseline, when participants were unaware of the speech task, and then prior to the speech using the six-item short-form of the State-Trait Anxiety Inventory (Marteau \& Bekker, 1992). An example item is "I feel stressed". Responses were measured on a five-point Likert scale from 1 (not at all) to 5 (very much). 
2.2.5 Observer-rated speech performance. Two raters watched video recordings of each participant's speech and rated various aspects of their speech performance. This included three items that we selected as indicators of the quality of speech performance: "the overall assuredness of the speaker", "the intellectual engagement of the speaker", and "how well structured was the speech". Responses for each item were scored on a seven-point Likert scale with higher scores reflecting better performance and we calculated a composite measure of performance by combining standardised scores for each item. The speech performance raters (one male, one female) were unaware of the study hypotheses and personality measure scores of participants. Each rater was instructed to carefully watch the entire speech and then immediately score the participant's performance on each criterion; both raters were compensated for their time. The intraclass correlation coefficient for the two raters overall performance scores was 0.82 .

2.2.6 Self-rated performance. We assessed participant's self-perceptions of speech performance using four items measuring their confidence with the topic ("Ifeel confident with the presentation topic I just delivered"), confidence with their own presentation ("I feel confident with the presentation I just delivered"), persuasiveness of the presentation ("Ifeel that the speech I just delivered can persuade other people”), and overall performance rating ("I think that, overall, my presentation is good"). Responses were measured on a seven-point Likert scale from 1 ( a little) to 7 (a lot). Self-ratings of performance were not recorded for three participants; thus, analysis for this variable was performed for the participants in the self-affirmation $(n=44)$ and control $(n=43)$ group with complete responses.

\subsection{Procedure}


Upon arrival to the testing room, we informed participants that the purpose of the study was to examine the effect of personality on communication. Participants completed measures of narcissism, baseline state anxiety and demographic information. In the self-affirmation condition (adapted from: Cohen, Garcia, Apfel, \& Master, 2006), participants first listed eleven personal values (e.g., creativity, humour) in order of their importance and then spent five minutes elaborating on the most important value. In the control condition, we asked participants to instead elaborate on a neutral topic: the items within their wardrobe.

We then informed participants that the true purpose of the study was to examine their public speaking ability and they would be required to deliver a short speech on the topic "What are the characteristics of an ideal student from this University?". The speech topic was chosen because of its relevance across participants, thus limiting the possibility that performance would be affected by knowledge. Participants then completed the self-integrity scale (Sherman et al., 2009), Rosenberg self-esteem scale (RSE; Rosenberg, 1979), and state-trait anxiety inventory (Marteau \& Bekker, 1992) to assess speech anxiety. After completing the scales, participants spent two minutes preparing their speech with a timer on the table for them to see before sitting in front of a video camera to deliver the presentation. We instructed participants to speak for five minutes, if they stopped speaking before five minutes elapsed, they were asked by the experimenter to continue speaking on the topic. To increase the realism of the speaking task, the room was setup to mimic a recording studio with professional lighting, backing screen, and a monitor displaying the live video recording. To increase the importance and self-enhancement potential for performing well on the task, we told participants that their speech would be shared publicly within the university campus as part of a project to encourage students' moral behaviour. After the presentation, participants provided self-ratings of their performance. 
Researchers then fully debriefed participants of the true purposes of the experiment and ensured participants understood the rationale behind the experimental protocol.

\subsection{Data Analysis}

We performed linear regression analysis in $R$, to test the main and interaction effects of narcissistic admiration, narcissistic rivalry and condition to predict our three dependent variables: anxiety, observer-rated performance, and self-rated performance. All predictors were standardised prior to being entered into the model. We examined the effect of condition with the control condition set as the reference, i.e., dummy coded 0 , and the self-affirmation condition coded 1. Because there is considerable overlap between narcissistic constructs and self-esteem (Sedikides, Rudich, Gregg, Kumashiro, \& Rusbult, 2004), we controlled for self-esteem in all analyses. Further, because narcissism is consistently higher in men than women (e.g., Foster, Campbell, \& Twenge, 2003), we also included sex as a covariate in all analyses; sex was coded 0 $=$ female and $1=$ male. As a measure of effect size, we report the semi-partial correlation squared $\left(s r^{2}\right)$, indicating the variance uniquely associated with the criterion variable; $2 \%, 13 \%$ and $26 \%$ reflect small, medium and large effect sizes, respectively. All significance tests are twotailed.

\section{Results}

\subsection{Preliminary Analyses}

Independent $t$-tests revealed no significant group differences (self-affirmation versus control) in age, narcissistic admiration, narcissistic rivalry, and self-esteem; all $p$-values > .22. We examined whether the self-affirmation manipulation was effective using an independent $t$ test to compare participant's self-integrity scores in the control $(M=28.78)$ and self-affirmation $(M=29.20)$ condition; this revealed no significant difference, Welch's $t(83.96)=0.47, p=.639$. 
Consequently, subsequent effects reported for condition should be interpreted with caution. On average, participants found the speaking task stressful; a paired samples $t$-test indicated a significant increase in state anxiety from baseline level $(M=4.57)$ in response to the speaking task $(M=6.46), t(89)=11.60, p<.001$.

\subsection{Main Analyses}

3.2.1 State anxiety. Entering covariates in the linear regression model to predict selfreported state anxiety revealed that self-esteem $\left(s r^{2}=.18\right)$ was negatively related to state anxiety whereas sex was unrelated to anxiety. In the second model, examining main effects of predictors, narcissistic admiration predicted significantly lower state anxiety $\left(s r^{2}=.05\right)$ whereas narcissistic rivalry predicted significantly higher state anxiety $\left(s r^{2}=.08\right)$. The self-affirmation condition was unrelated to state anxiety. Further, self-affirmation did not interact with either admiration or rivalry to predict anxiety. We also examined the same regression model whilst entering baseline state anxiety as a covariate, this had no substantive effect on any of the estimates reported (see supplementary).

3.2.2 Observer-rated performance. Self-esteem and sex were unrelated to speech performance. In the second model, narcissistic admiration predicted significantly better speech performance $\left(s r^{2}=.08\right)$, whereas narcissistic rivalry was unrelated to speech performance. The self-affirmation condition was also unrelated to performance. When examining the interaction effects, the self-affirmation condition did not moderate the relationship between admiration or rivalry and speech performance.

3.2.3 Self-rated performance. Sex was unrelated to self-rated performance whereas selfesteem was a predictor $\left(s r^{2}=.09\right)$. Narcissistic admiration was associated with significantly higher performance ratings $\left(s r^{2}=.18\right)$, whereas narcissistic rivalry was unrelated to performance. 
The self-affirmation condition was positively associated with self-rated performance $\left(s r^{2}=.04\right)$, indicating that participants believed their performance was better in the self-affirmation condition compared to the control condition. When examining the interaction effects, the selfaffirmation condition did not moderate the admiration - performance relation. However, we observed a significant rivalry $\times$ condition interaction $\left(s r^{2}=.04\right)$. Simple slopes analysis revealed a statistically significant negative relationship between narcissistic rivalry and performance in the self-affirmation condition, $t(79)=-2.49, \beta=-1.81, p=.01$; narcissistic rivalry was unrelated to performance in the control condition, $t(79)=0.53, \beta=0.42, p=.60$.

Table 1

Zero-order correlations, means, standard deviation and reliability of key variables

\begin{tabular}{lccccccccc}
\hline & & & & & & & & $M$ & $S D$ \\
& 1 & 2 & 3 & 4 & 5 & 6 & 7 & (Control) \\
\hline 1. State Anxiety & & & & & & & & \\
2. Self-Esteem & - & $-.40^{* *}$ & $-.46^{* *}$ & .15 & $-.39 * *$ & -.20 & -.14 & 19.09 & 5.19 \\
3. Narcissistic Admiration & $-.46^{* *}$ & - & $.47^{* *}$ & $-.31^{*}$ & .26 & .10 & -.07 & 37.11 & 6.51 \\
4. Narcissistic Rivalry & -.15 & $.38^{*}$ & - & .12 & $.57^{* *}$ & .22 & .21 & 3.58 & 0.69 \\
5. Self-Rated Performance & $.52^{* *}$ & $-.47^{* *}$ & .24 & - & .16 & .06 & .33 & 2.03 & 0.66 \\
6. Observer-Rated Performance & $-.58^{* *}$ & $.31^{*}$ & $.47^{* *}$ & -.22 & - & $.61^{* *}$ & .22 & 12.32 & 5.29 \\
7. Sex & .07 & -.08 & .32 & .07 & $.51^{* *}$ & - & .19 & -1.34 & 6.43 \\
$\quad \alpha$ & .86 & .89 & .76 & .84 & .90 & .94 & & & \\
M (self-affirmation) & 19.02 & 37.14 & 3.68 & 2.20 & 14.60 & 1.40 & & & \\
SD (self-affirmation) & 4.40 & 7.01 & 0.72 & 0.80 & 5.09 & 5.65 & & & \\
\hline
\end{tabular}

Note. ${ }^{*} p<.05, * * p<.01$, two-tailed. $\alpha=$ Cronbach's alpha for overall scale reliability across groups in present sample. Correlations for the control and self-affirmation groups are presented above and below the diagonal, respectively. Sex coded: $0=$ female, $1=$ male.

Table 2.

Moderated hierarchical regression to predict state anxiety, observer-rated and self-rated speech performance 


\begin{tabular}{|c|c|c|c|c|c|c|c|c|c|}
\hline \multirow{2}{*}{$\begin{array}{l}\text { State } \\
\text { anxiety }\end{array}$} & \multicolumn{3}{|c|}{ Model 1} & \multicolumn{3}{|c|}{ Model 2} & \multicolumn{3}{|c|}{ Model 3} \\
\hline & $\mathrm{B}$ & SE B & $p$ & $\mathrm{~B}$ & SE B & $p$ & $\mathrm{~B}$ & SE B & $p$ \\
\hline (Intercept) & 19.29 & 0.53 & $<.001$ & 19.46 & 0.68 & $<.001$ & 19.33 & 0.68 & $<.001$ \\
\hline Sex & -0.97 & 1.08 & .372 & -1.20 & 1.11 & .283 & -1.15 & 1.10 & .299 \\
\hline Self-esteem & -2.06 & 0.47 & $<.001$ & -0.84 & 0.58 & .154 & -0.76 & 0.58 & .189 \\
\hline Condition & & & & -0.23 & 0.89 & .792 & -0.21 & 0.88 & .813 \\
\hline Admiration & & & & -1.36 & 0.55 & .016 & -2.13 & 0.71 & .003 \\
\hline Rivalry & & & & 1.67 & 0.55 & .003 & 1.06 & 0.74 & .155 \\
\hline \multicolumn{4}{|c|}{ Admiration $\times$ Condition } & & & & 1.39 & 0.89 & .123 \\
\hline \multicolumn{4}{|c|}{ Rivalry $\times$ Condition } & & & & 1.02 & 0.91 & .269 \\
\hline & \multicolumn{3}{|c|}{$\begin{array}{c}\mathrm{F}(2,87)=4.37, \mathrm{p}<.001 \\
\text { Multiple } R^{2}=.19 \\
\text { Adjusted } R^{2}=.17\end{array}$} & \multicolumn{3}{|c|}{$\begin{array}{c}\mathrm{F}(5,84)=4.18, \mathrm{p}<.001 \\
\text { Multiple } R^{2}=.28 \\
\text { Adjusted } R^{2}=.24\end{array}$} & \multicolumn{3}{|c|}{$\begin{array}{c}\mathrm{F}(7,82)=4.12, \mathrm{p}<.001, \\
\text { Multiple } R^{2}=.32 \\
\text { Adjusted } R^{2}=.26\end{array}$} \\
\hline \multicolumn{10}{|c|}{$\begin{array}{l}\text { Observer-rated } \\
\text { performance }\end{array}$} \\
\hline & $\mathrm{B}$ & SE B & $p$ & $\mathrm{~B}$ & SE B & $p$ & $\mathrm{~B}$ & SE B & $p$ \\
\hline (Intercept) & -0.13 & 0.35 & .694 & -0.44 & 0.45 & .330 & -0.43 & 0.46 & .351 \\
\hline Sex & 0.56 & 0.70 & .429 & 0.03 & 0.73 & .967 & -0.01 & 0.73 & .986 \\
\hline Self-esteem & 0.06 & 0.30 & .851 & -0.45 & 0.38 & .236 & -0.47 & 0.39 & .229 \\
\hline Condition & & & & 0.88 & 0.58 & .134 & 0.88 & 0.59 & .140 \\
\hline Admiration & & & & 0.98 & 0.36 & .008 & 0.89 & 0.47 & .062 \\
\hline Rivalry & & & & -0.18 & 0.36 & .607 & -0.06 & 0.50 & .896 \\
\hline \multicolumn{4}{|c|}{ Admiration $\times$ Condition } & & & & 0.19 & 0.60 & .746 \\
\hline \multicolumn{4}{|c|}{ Rivalry $\times$ Condition } & & & & -0.23 & 0.61 & .709 \\
\hline & \multicolumn{3}{|c|}{$\begin{array}{c}F(2,87)=2.84, \mathrm{p}=.726 \\
\text { Multiple } R^{2}=.01 \\
\text { Adjusted } R^{2}=-.01\end{array}$} & \multicolumn{3}{|c|}{$\begin{array}{c}F(5,84)=2.73, \mathrm{p}=.060 \\
\text { Multiple } R^{2}=.12 \\
\text { Adjusted } R^{2}=.06\end{array}$} & \multicolumn{3}{|c|}{$\begin{array}{c}F(7,82)=2.76, \mathrm{p}=.154 \\
\text { Multiple } R^{2}=.12 \\
\text { Adjusted } R^{2}=.04\end{array}$} \\
\hline \multicolumn{10}{|l|}{$\begin{array}{l}\text { Self-rated } \\
\text { performance }\end{array}$} \\
\hline & $\mathrm{B}$ & SE B & $p$ & $\mathrm{~B}$ & SE B & $p$ & $\mathrm{~B}$ & SE B & $p$ \\
\hline (Intercept) & 12.99 & 0.63 & $<.001$ & 12.29 & 0.75 & $<.001$ & 12.49 & 0.74 & $<.001$ \\
\hline Sex & 1.87 & 1.26 & .142 & 0.56 & 1.19 & .637 & 0.40 & 1.17 & .735 \\
\hline Self-esteem & 1.53 & 0.54 & .006 & -0.04 & 0.62 & .943 & -0.20 & 0.61 & .745 \\
\hline Condition & & & & 2.07 & 0.97 & .035 & 2.05 & 0.95 & .033 \\
\hline Admiration & & & & 2.79 & 0.59 & $<.001$ & 3.08 & 0.75 & $<.001$ \\
\hline Rivalry & & & & -0.83 & 0.59 & .166 & 0.42 & 0.79 & .598 \\
\hline \multicolumn{4}{|c|}{ Admiration $\times$ Condition } & & & & -0.27 & 0.95 & .780 \\
\hline \multicolumn{4}{|c|}{ Rivalry $\times$ Condition } & & & & -2.23 & 0.97 & .025 \\
\hline & \multicolumn{3}{|c|}{$\begin{array}{c}F(2,84)=4.73, \mathrm{p}=.011 \\
\text { Multiple } R^{2}=.10 \\
\text { Adjusted } R^{2}=.08\end{array}$} & \multicolumn{3}{|c|}{$\begin{array}{c}F(5,81)=4.46, \mathrm{p}<.001 \\
\text { Multiple } R^{2}=.33 \\
\text { Adjusted } R^{2}=.29\end{array}$} & \multicolumn{3}{|c|}{$\begin{array}{c}F(7,79)=4.36, \mathrm{p}<.001 \\
\text { Multiple } R^{2}=.38 \\
\text { Adjusted } R^{2}=.32\end{array}$} \\
\hline
\end{tabular}


Note. Sex coded: $0=$ female, $1=$ male. Condition coded: $0=$ control group, $1=$ self-affirmation group. The direction and statistical significance of all effects reported remain unchanged when removing sex as a covariate.

\section{Discussion}

Here, we asked whether the different processes associated with narcissistic admiration (agentic self-promotion) and rivalry (antagonistic self-defence) would result in these two dimensions having different effects on anxiety and speaking performance. Hypothesis 1 was fully supported with admiration associated with lower self-reported state anxiety and higher observer-rated and self-rated speech performance. Hypothesis 2 was supported with regard to anxiety but not for speech performance; rivalry predicting higher self-reported state anxiety but, in contrast to our expectations, we found no effect of rivalry on self and observer-rated speech performance. Thus, in the current sample, the antagonistic and defensive motivations associated with rivalry did not appear to exert a detrimental effect on how others perceive their performance.

Our final, and more speculative, hypothesis was that self-affirmation may attenuate any negative effect of rivalry on speech performance and anxiety. Hypothesis 3 was not supported; we observed no moderation effect for anxiety and observer-rated speech performance and observed the opposite of predicted effect for rivalry and self-rated speech performance. Rivalry was negatively related to self-rated speech performance following self-affirmation, while rivalry was unrelated to self-rated speech performance in the control condition. One tentative explanation for why this occurred is that the self-affirmation made individuals less defensive about their performance evaluation and thus more willing to identify and report inadequacies in their performance. Alternatively, the affirmation intervention may have had a paradoxical effect 
on those high in rivalry by highlighting discrepancies between the lofty affirmations they are making and the self-perceptions they hold (Wood, Perunovic, \& Lee, 2009). However, an important caveat to any speculation of the interaction effect of self-affirmations and rivalry is that our manipulation check (self-integrity scale scores) examining the efficacy of the affirmations revealed no difference between the control and affirmation group, suggesting that the affirmation intervention could have been ineffective. This lack of effect for the manipulation may also explain why we observed no beneficial effects of the self-affirmation intervention. A second caveat to examining any interaction between the self-affirmation intervention and narcissism is that the study was underpowered to detect these effects.

\subsection{Generalizability, limitations and future directions}

The speaking task we used in the present study is similar to what has been adopted in previous studies examining public speaking (e.g., Carrillo et al., 2001) and we made additional efforts to make the task appear consequential, realistic and thereby induced an increase in anxiety. However, despite these efforts, our experimental speech task was artificial in nature (e.g., no audience, short preparation time, etc.) and it is inevitable that there are quantitative and qualitative differences compared to what individuals may experience when delivering a speech in real-life to a large audience. Thus, future research examining the effect of narcissism on natural speech performance is encouraged. Naturalistic settings would also be worthwhile because they remove the need for deception that was necessary in our lab set up. While our approach regarding the perceived public nature of evaluation was consistent with previous narcissismperformance studies (e.g., Wallace \& Baumeister, 2002), we do note that naturalistic settings would be good places to test these hypotheses in the future, so as to avoid the need to engage with deception and any confounds that such deception might cause on obtained effects. 
It is also true that the influence of admiration and rivalry on speech performance may vary as a function of the situational dynamics of the speech, e.g., the relative status of the audience and speaker, the consequences, etc. For example, when giving a low consequence speech to peers (e.g., a toast at a birthday) there is likely to be much less ego-threat than when delivering a consequential speech to high status audience (e.g., during a job interview). Thus, it is reasonable to expect that narcissistic dimensions (primarily rivalry) would exert a much stronger influence on speech performance in these domains where ego-threat is likely to be induced, e.g., when the audience contains high status evaluators (Horton \& Sedikides, 2009). Similarly, the present task did not have a strong interpersonal element; this is potentially important given that in real life public speaking, people readily pick up cues that signal performance feedback (e.g., a raised eyebrow indicating surprise or disapproval). In a dyadic task one might imagine that narcissistic admiration would predict increases in effort when observing that others are either not enjoying the speech or not giving desired levels of attention. In contrast, if one perceives others to be in disagreement with the content of your speech, rivalry may only then be critical in triggering antagonistic responses leading to a more defensive or aggressive style of speech. Finally, it is noteworthy that our sample was primarily a young, largely female, student cohort. Thus, our effects may not generalize to other groups of individuals who vary on admiration and rivalry. Testing the generalizability of the effects reported here would be worthwhile for future research.

\subsection{Conclusion}

In summary, whereas admiration appears to have a clear facilitative effect on speech performance, the effects of rivalry are less clear. Overall, our results add to the developing literature on the behavioural correlates of narcissistic admiration and rivalry and support the 
benefit of conceptualising narcissism according to two distinct dimensions rather than as a single grandiose component. 


\section{Funding}

This research did not receive any specific grant from funding agencies in the public, commercial, or not-for-profit sectors.

\section{Acknowledgements}

We thank Tanikarn Maneekhao and Prapimpa Jarunratanakul for assistance with data collection. 


\section{References}

Back, M. D., Küfner, A. C. P., Dufner, M., Gerlach, T. M., Rauthmann, J. F., \& Denissen, J. J. A. (2013). Narcissistic admiration and rivalry: Disentangling the bright and dark sides of narcissism. Journal of Personality and Social Psychology, 105(6), 1013-1037. https://doi.org/10.1037/a0034431

Brislin, R. W. (1970). Back-Translation for Cross-Cultural Research. Journal of Cross-Cultural Psychology, 1(3), 185-216. https://doi.org/10.1177/135910457000100301

Bushman, B. J., \& Baumeister, R. F. (1998). Threatened egotism, narcissism, self-esteem, and direct and displaced aggression: does self-love or self-hate lead to violence? Journal of Personality and Social Psychology, 75(1), 219-229. https://doi.org/10.1037/00223514.75.1.219

Carrillo, E., Moya-Albiol, L., Gonzalez-Bono, E., Salvador, A., Ricarte, J., \& Gomez-Amor, J. (2001). Gender differences in cardiovascular and electrodermal responses to public speaking task: the role of anxiety and mood states. International Journal of Psychophysiology, 42(3), 253-264. https://doi.org/S0167-8760(01)00147-7 [pii]

Cohen, G. L., Garcia, J., Apfel, N., \& Master, A. (2006). Reducing the racial achievement gap: A social-psychological intervention. Science, 313, 1307-1310. https://doi.org/10.1126/science. 1128317

Creswell, J. D., Creswell, J. D., Welch, W. T., Welch, W. T., Taylor, S. E., Taylor, S. E., ... Mann, T. (2005). Affirmation of Personal Values Buffers Neuroendocrine and Psychological Stress Responses. Society, 16(11), 846-852. https://doi.org/10.1111/j.14679280.2005.01624.x

Crowe, M. L., Lynam, D. R., Campbell, W. K., \& Miller, J. D. (2019). Exploring the structure of 
narcissism: Toward an integrated solution. Journal of Personality, (January). https://doi.org/10.1111/jopy.12464

Dufner, M., Egloff, B., Hausmann, C. M., Wendland, L. M., Neyer, F. J., \& Back, M. D. (2015). Narcissistic Tendencies Among Actors: Craving for Admiration, But Not at the Cost of Others. Social Psychological and Personality Science, 6(4), 447-454. https://doi.org/10.1177/1948550614564224

Faul, F., Erdfelder, E., Lang, A.-G., \& Buchner, A. (2007). G*Power 3: a flexible statistical power analysis program for the social, behavioral, and biomedical sciences. Behavior Research Methods, 39, 175-191. https://doi.org/10.3758/BF03193146

Foster, J. D., Campbell, W. K., \& Twenge, J. M. (2003). Individual differences in narcissism: Inflated self-views across the lifespan and around the world. Journal of Research in Personality, 37(6), 469-486. https://doi.org/10.1016/S0092-6566(03)00026-6

Grove, J. L., Smith, T. W., Girard, J. M., \& Wright., A. G. (2019). Narcissistic Admiration and Rivalry: An Interpersonal Approach to Construct Validation. Journal of Personality Disorders, 33, 1-25. https://doi.org/http://doi.org/10.1521/pedi_2019_33_374

Horton, R. S., \& Sedikides, C. (2009). Narcissistic responding to ego threat: When the status of the evaluator matters. Journal of Personality, 77(5), 1493-1525. https://doi.org/10.1111/j.1467-6494.2009.00590.x

Kirschbaum, C., Pirke, K. M., \& Hellhammer, D. H. (1993). The 'Trier Social Stress Test'--a tool for investigating psychobiological stress responses in a laboratory setting. Neuropsychobiology, 28(1-2), 76-81. https://doi.org/10.1159/000119004

Krizan, Z., \& Herlache, A. D. (2018). The Narcissism Spectrum Model : A Synthetic View of Narcissistic Personality. Personality and Social Psychology Review, 22(1), 3-31. 
https://doi.org/10.1177/1088868316685018

Leckelt, M., Küfner, A. C. P., Nestler, S., \& Back, M. D. (2015). Behavioral processes underlying the decline of narcissists ' popularity over time. Journal of Personality and Social Psychology, 109(5), 856-871. https://doi.org/10.1037/pspp0000057

Manley, H., Jarukasemthawee, S., \& Pisitsungkagarn, K. (2019). The Effect of Narcissistic Admiration and Rivalry on Mental Toughness. Personality and Individual Differences.

Marteau, T. M., \& Bekker, H. (1992). The development of a six-item short-form of the state scale of the Spielberger State-Trait Anxiety Inventory ( STAI ), 301-306.

Miller, J. D., Lynam, D. R., Hyatt, C. S., \& Campbell, W. K. (2017). Controversies in Narcissism. Annual Review of Clinical Psychology, 13, 1.1-1.25. https://doi.org/10.1146/annurev-clinpsy-032816-045244

Roberts, R., Woodman, T., \& Sedikides, C. (2018). Pass Me the ball: Narcissism in performance settings. International Review of Sport and Exercise Psychology, 11(1), 190-213. https://doi.org/10.1080/1750984X.2017.1290815

Rosenberg, M. (1979). Conceiving the Self. New York: Basic Books.

Sedikides, C., Rudich, E. A., Gregg, A. P., Kumashiro, M., \& Rusbult, C. (2004). Are normal narcissists psychologically healthy?: Self-esteem matters. Journal of Personality and Social Psychology, 87, 400-416. https://doi.org/10.1037/0022-3514.87.3.400

Sherman, D. K., Cohen, G. L., Nelson, L. D., Nussbaum, A. D., Bunyan, D. P., \& Garcia, J. (2009). Affirmed yet unaware: Exploring the role of awareness in the process of selfaffirmation. Journal of Personality and Social Psychology, 97(5), 745-764. https://doi.org/10.1037/a0015451

Steele, C. M. (1988). The Psychology of self-affirmation: Sustaining the integrity of the self. In 
L. Berkowitz (Ed.), Advances in experimental social psychology (Vol. 21, pp. 261-302). New York: Academic Press. https://doi.org/10.1016/S0065-2601(08)60229-4

Thomaes, S., Bushman, B. J., Castro, B. O. De, Cohen, G. L., Denissen, J. J. A., Orobio De Castro, B., ... Denissen, J. J. A. (2016). Reducing Narcissistic Aggression by Buttressing Self-Esteem An Experimental Field Study. Psychological Science, 20(12), 1536-1542. https://doi.org/10.1111/j.1467-9280.2009.02478.x

Twenge, J. M., \& Campbell, W. K. (2003). 'Isn't it fun to get the respect that we're going to deserve?" Narcissism, social rejection, and aggression. Personality and Social Psychology Bulletin, 29(2), 261-272. https://doi.org/10.1177/0146167202239051

Wallace, H. M., \& Baumeister, R. F. (2002). The performance of narcissists rises and falls with perceived opportunity for glory. Journal of Personality and Social Psychology, 82(5), 819834. https://doi.org/10.1037//0022-3514.82.5.819

Wood, J. V, Perunovic, W. Q. E., \& Lee, J. W. (2009). Positive self statements: Power for some, peril for others. Psychological Science., 20(7), 860-866. https://doi.org/https://doi.org/10.1111\%2Fj.1467-9280.2009.02370.x 